\title{
Relations between QRS|T Angle, Cardiac Risk Factors, and Mortality in the Third National Health and Nutrition Examination Survey (NHANES III)
}

\author{
William Whang, MS, MS ${ }^{\mathrm{a}}$, Daichi Shimbo, MDa , Emily B. Levitan, ScD ${ }^{\mathrm{b}}$, Jonathan $\mathrm{D}$. \\ Newman, MD, MPH ${ }^{\mathrm{a}}$, Pentti M. Rautaharju, MD, PhD $^{\mathrm{C}}$, Karina W. Davidson, PhDa, and Paul \\ Muntner, PhD ${ }^{\mathrm{b}}$ \\ ${ }^{a}$ Center for Behavioral Cardiovascular Health, Department of Medicine, Columbia University \\ Medical Center, New York, NY \\ ${ }^{b}$ Department of Epidemiology, University of Alabama at Birmingham, AL \\ 'Wake Forest University School of Medicine, Winston-Salem, NC
}

\section{Abstract}

On the surface electrocardiogram (ECG), an abnormally wide QRS|T angle reflects changes in regional action potential duration profiles and in direction of repolarization sequence which is thought to increase the risk of ventricular arrhythmia. We investigated the relationship between abnormal QRS|T angle and mortality in a nationally representative sample of individuals without clinically evident heart disease. We studied 7,052 participants $\geq 40$ years of age in the Third National Health and Nutrition Examination Survey (NHANES III) with 12-lead ECGs. Individuals with self-report or ECG evidence of a prior myocardial infarction, QRS duration $\geq 120 \mathrm{msec}$, or history of heart failure were excluded. Borderline and abnormal spatial QRS|T angle were defined according to sex-specific $75^{\text {th }}$ and $95^{\text {th }}$ percentiles of frequency distributions. All-cause $(n=1093$ women, $n=1191$ men) and cardiovascular mortality ( $n=462$ women, $n=455$ men) over 14 years was assessed through linkage with the National Death Index. In multivariable analyses, abnormal spatial QRS|T angle was associated with an increased hazard ratio (HR) for cardiovascular mortality in women (HR 1.82, 95\% CI 1.05-3.14) and men (HR 2.21, 95\% CI 1.32-3.68). An abnormal QRS|T angle was also associated with increased multivariable adjusted HRs for allcause mortality in women (HR 1.30, 95\% CI 0.95-1.78) and men (HR 1.87, 95\% CI 1.29-2.7). Borderline QRS|T angle was not associated with increased risk for all-cause or cardiovascular mortality. In conclusion, abnormal QRS|T angle, as measured on a 12-lead ECG, was associated with increased risk for cardiovascular and all-cause mortality in this population-based sample without known heart disease.

\section{Keywords}

electrocardiogram; cardiac mortality; QRS|T angle; epidemiology

(C) 2011 Excerpta Medica, Inc. All rights reserved.

Corresponding author: William Whang, MD, PH9-321, 622 West $168^{\text {th }}$ Street, New York, NY 10032. Telephone: 212-305-8620. Fax 212-305-3137.ww42@mail.cumc.columbia.edu.

Publisher's Disclaimer: This is a PDF file of an unedited manuscript that has been accepted for publication. As a service to our customers we are providing this early version of the manuscript. The manuscript will undergo copyediting, typesetting, and review of the resulting proof before it is published in its final citable form. Please note that during the production process errors may be discovered which could affect the content, and all legal disclaimers that apply to the journal pertain. 


\section{Introduction}

Measures on the 12-lead electrocardiogram (ECG), such as the QT interval, left ventricular hypertrophy, and ST segment depression, are known to provide prognostic information for cardiovascular morbidity and mortality. ${ }^{1-4}$ Spatial QRS|T angle quantifies the deviation in the direction of ventricular depolarization and repolarization. Abnormally wide QRS|T angle reflects changes in regional action potential duration profiles and in spatial direction of repolarization sequence, which may be associated with increased dispersion of repolarization and malignant arrhythmia. ${ }^{5}$ Abnormal spatial QRS|T angle has been associated with all-cause mortality, cardiac mortality, and sudden cardiac death in several cohorts. ${ }^{3,6-9}$ One prior study has evaluated the relationship between QRS|T angle and mortality in individuals without heart disease, ${ }^{6}$ and it remains unconfirmed if QRS|T angle is a useful clinical predictor of cardiac outcomes in the general population. We hypothesized that spatial QRS|T angle, determined from a 12-lead ECG, is an independent predictor of cardiovascular and all-cause mortality in the general population without known cardiac disease, and we sought to examine this question in the Third National Health and Nutrition Examination Survey (NHANES III). A second aim of this study was to determine clinical correlates associated with abnormal spatial QRS|T angle.

\section{Methods}

NHANES III was a stratified, multistage probability survey designed to select a representative sample of the civilian non-institutionalized United States population. Overall, 10,294 adults 40 years of age and older completed the NHANES III interview and examination between 1988 and 1994. We excluded 1,809 participants who did not have a 12-lead ECG, 775 participants with a self-report or ECG evidence of a prior myocardial infarction, 192 with a history of congestive heart failure, 452 participants with a QRS interval $\geq 120 \mathrm{msec}$, and 14 participants without valid ECG data for calculating spatial QRS| $T$ angle. After these exclusions, a total of 7,052 NHANES III participants were included in the current analyses. Compared with those who were included in this analysis, the 1809 participants who were excluded due to missing ECGs were noted to be older $(63.0 \pm 0.7$ years versus 55.90 .4 years, $\mathrm{p}<0.001)$ and more likely to be non-Hispanic black race $(15.0 \%$ versus $8.9 \%, \mathrm{p}<0.001$ ). The protocol for NHANES III was approved by the National Center for Health Statistics of the Center for Disease Control and Prevention Institutional Review Board. All participants gave written informed consent.

NHANES III baseline data were collected during an in-home interview and a subsequent visit to a mobile examination center. Data collected during the in-home interview included demographics, physical activity, smoking, use of antihypertensive and cholesterol lowering medication, and a history of stroke.

Using height and weight measured during the visit to the mobile examination center, body mass index was calculated as weight in kilograms divided by height in meters squared. Blood pressure was measured three times during the in-home interview and three additional times during the visit to the mobile examination center. All blood pressure measurements for each participant were averaged. Serum C-reactive protein was quantified using latexenhanced nephelometry, a low sensitivity assay, and levels $\geq 3 \mathrm{mg} / \mathrm{L}$ were defined as elevated. Plasma glucose was measured using an enzymatic reaction. Diabetes mellitus was defined as a fasting plasma glucose $\geq 126 \mathrm{mg} / \mathrm{dL}$, a non-fasting plasma glucose $\geq 200 \mathrm{mg} / \mathrm{dL}$ and/or a self-reported history of diabetes with concurrent use of anti-diabetes medication. Total serum cholesterol and HDL-cholesterol were measured enzymatically. Serum creatinine was measured by the Jaffe modified kinetic method. Estimated glomerular filtration rate (eGFR) was calculated using the Chronic Kidney Disease Epidemiology 
Collaboration (CKD-EPI) equation after aligning the serum creatinine concentrations with the assay employed in the development of the equation. ${ }^{10,11}$ Reduced eGFR was defined as $<60 \mathrm{ml} / \mathrm{min} / 1.73 \mathrm{~m}^{2}$. A spot urine sample was collected and albuminuria defined as a urinary albumin to creatinine concentration $\geq 30 \mathrm{mg} / \mathrm{g}$.

ECGs were recorded on a Marquette MAC 12 system (Marquette Medical Systems, Inc. Milwaukee, WI) by trained technicians during the participant's visit to the mobile examination center. Computerized analysis of the ECG data was performed using Minnesota ${ }^{12}$ and Novacode ${ }^{13}$ algorithms. Coding included rhythm analysis, detection of ECG abnormalities, and selective averaging to obtain representative durations and amplitudes of ECG components.

The spatial QRS|T angle was approximated by a simple algorithm derived from ECG data file of the Atherosclerosis Research in Communities (ARIC) study, ${ }^{14}$ which uses a combination of 3 QRS and 3 T wave peak-to-peak amplitudes available in the NHANES III public release ECG data file. The reported correlation between QRS|T angle from the simple algorithm and that from matrix transformation of the 12-lead ECGs was 0.87, and the sensitivity of this simple method for detecting abnormal QRS|T angle was 0.88 and the specificity was 0.91 .

We classified spatial QRS|T angle two ways. First, we categorized QRS|T angle values according to the sex-specific frequency distribution as abnormal ( $\geq 95$ th percentile), borderline ( $\geq 75$ th and $<95^{\text {th }}$ percentile), and normal ( $<75$ th percentile) as previously described. ${ }^{6}$ The $75^{\text {th }}$ and $95^{\text {th }}$ percentiles were $90^{\circ}$ and $121^{\circ}$ for women, respectively, and $107^{\circ}$ and $136^{\circ}$ for men, respective ly. Second, based on a prior study in an elderly sample we categorized spatial QRS|T angle as abnormal $\left(135\right.$ to $\left.180^{\circ}\right)$, borderline $\left(105\right.$ to $\left.135^{\circ}\right)$ and normal $\left(0\right.$ to $\left.105^{\circ}\right){ }^{7}$

In addition, we calculated frontal plane $\mathrm{QRS} \mid \mathrm{T}$ angle as the absolute difference between the frontal plane QRS axis and T axis. ${ }^{6}$ We defined normal, borderline, and abnormal frontal plane QRS|T angle according to the sex-specific $75^{\text {th }}\left(39^{\circ}\right.$ and $81^{\circ}$ for women and men, respectively) and $95^{\text {th }}\left(43^{\circ}\right.$ and $95^{\circ}$ for women and men, respectively) percentiles of its distribution.

NHANES III participants have been followed for mortality through December 31, 2006. The method of probabilistic matching was used to link NHANES III participants with the National Death Index to identify vital status and, for those who died, cause of death. Matching was based on 12 identifiers for each participant including Social Security number, sex, and date of birth. Follow-up for each study participant was calculated as the time between their NHANES III examination and the date of death or December 31, 2006, whichever occurred first. Cause of death was determined using the underlying cause listed on death certificates. The ICD-9 was used for deaths occurring between 1988 and 1998 and ICD-10 for deaths during 1999 and 2006. Cardiovascular (CVD) mortality was defined by any of ICD-9 codes 390-434 and 436-459; ICD-10 codes I00-I99.

As the distribution of the QRS|T angle may differ for men and women, a priori, we chose to conduct all analyses stratified by sex. Baseline characteristics of the study population, mean or percentage, were calculated for each level of spatial QRS|T angle (normal, borderline, or abnormal). Using logistic regression models, factors associated with abnormal spatial QRS|T angle were calculated. Factors investigated included age, race/ethnicity, heart rate, being physically inactive, current smoking, body mass index, systolic blood pressure, antihypertensive medication use, total and high-density lipoprotein cholesterol, cholesterol lowering medication use, elevated C-reactive protein, diabetes, reduced eGFR, albuminuria, 
and history of stroke, simultaneously. Initial models included age and race/ethnicity with subsequent models including all variables simultaneously.

Cox proportional hazards regression was used to calculate the age-race/ethnicity and multivariable adjusted hazard ratios and $95 \%$ confidence intervals (CI) for all-cause and CVD-related mortality associated with borderline and abnormal, compared to normal, spatial QRS|T angle. The multivariable adjusted hazard ratio for all-cause and CVD-related mortality were also calculated for spatial QRS|T angle modeled as a continuous variable using restricted quadratic splines with knots at the $75^{\text {th }}$, and $95^{\text {th }}$ percentiles of the spatial QRS|T distribution. Two sensitivity analyses were conducted. First, the age-race/ethnicity and multivariable adjusted hazard ratios for all-cause and cardiovascular mortality were calculated using cut-points of $<135^{\circ}, 105$ to $135^{\circ}$, and $\geq 135^{\circ}$ to define normal, borderline, and abnormal spa tial QRS|T angles, respectively. Second, hazard ratios were calculated for borderline and abnormal, versus normal frontal plane QRS|T angle.

Data were analyzed using SUDAAN (version 9.0; Research Triangle Institute, Research Triangle Park, NC) to account for the complex NHANES sampling design, including data clustering and unequal probabilities of selection, over-sampling, and non-response.

NHANES III sampling weights were applied in all analyses.

\section{Results}

Baseline characteristics of women and men included in this analysis, according to normal, borderline and abnormal spatial QRS|T angle, are presented in Table 1. Men and women with an abnormal QRS|T angle were older and more likely to be non-Hispanic black. In ageand race-adjusted, gender specific analyses, body mass index, systolic blood pressure, antihypertensive medication use, diabetes mellitus, and albuminuria were associated with abnormal QRS|T angle. After multivariable adjustment, smoking, systolic blood pressure and albuminuria were associated with abnormal QRS|T angle in women (Table 2), while in men only cholesterol-lowering medication use and diabetes mellitus were associated with abnormal QRS|T angle.

Over a median follow-up of 14 years, mortality both in women and men was highest among those with abnormal QRS|T angle, followed by those with borderline QRS|T angle (Table 3). After adjustment for age and race/ethnicity, among both men and women, abnormal $\mathrm{QRS} \mid \mathrm{T}$ angle was associated with an increased hazard ratio for all-cause and cardiovascular mortality. After multivariable adjustment, abnormal QRS|T angle was associated with a nonsignificant elevated risk of all-cause mortality in women and with significantly increased risk in men. Abnormal QRS|T angle was significantly associated with increased risk of cardiovascular mortality both in women and in men. The associations with all-cause and cardiovascular mortality were similar when using pre-specified levels for defining borderline and abnormal QRS|T angle (Table 4). In both women and men, abnormal QRS|T angle according to pre-specified levels was significantly associated both with all-cause mortality and cardiovascular mortality in multivariable analyses. When analyzed as a continuous variable, the risk of all-cause and cardiovascular mortality increased substantially for QRS|T angle values approximately $>90^{\circ}$, whereas for men the mortality $\mathrm{r}$ isk increased at $\mathrm{QRS} \mid \mathrm{T}$ angle values approximately $>120^{\circ}$ (Figure 1).

Among men, abnormal frontal plane QRS|T angle was associated with increased risk for allcause and cardiovascular mortality in both age-race/ethnicity and multivariable adjusted models (Supplemental Table 1). In women, abnormal frontal plane QRS|T angle was not associated either with all-cause mortality or cardiovascular mortality after multivariable adjustment. 


\section{Discussion}

In the current analysis, an abnormal spatial QRS|T angle was a strong, independent predictor of long-term all-cause and cardiovascular mortality. Our results are similar to the finding by Zhang et al. in the Atherosclerosis Risk in Communities study of increased mortality risk in individuals without known heart disease. ${ }^{6}$ Our study extends prior analyses by utilizing a nationally representative sample of US adults without known heart disease to estimate the relationships between spatial QRS|T angle and cardiovascular mortality. In addition, we examined potential nonlinearity of the relationships. Of note, the spline analyses indicated that the mortality risk rises monotonically once threshold values for abnormal QRS|T angle are reached, and that these thresholds are different for men $\left(>120^{\circ}\right)$ and women $\left(>90^{\circ}\right)$.

In NHANES III, an abnormal QRS|T angle was associated with several known cardiovascular risk factors, most strongly with smoking, systolic blood pressure and albuminuria in women and with diabetes mellitus in men. Prior smaller studies have also documented relationships between abnormal QRS|T angle and blood pressure, ${ }^{1516}$ diabetes, ${ }^{17}$ and smoking. ${ }^{18}$ Compared with these studies, the current analysis used a larger sample size and adjusted for a greater number of potential confounders, allowing us to find that there were different clinical correlates of abnormal QRS|T angle depending on gender.

In this analysis we excluded participants with previous myocardial infarction, heart failure, and/or prolonged QRS duration, so that individuals with overt cardiac disease were less likely to be included. Our results suggest that an abnormal QRS|T angle as derived from a 12-lead ECG may be a marker for subclinical cardiac disease, as well as a mortality indicator. Based on our findings, abnormal QRS|T angle in individuals without known heart disease may warrant further clinical evaluation in order to manage cardiac risk factors, inform prognosis, and pursue potential treatments to reduce the cardiac mortality risk.

Our results also suggest a potential clinical utility, in men, of the frontal plane QRS|T angle, derived as the difference between QRS axis and T axis available in the reports of most ECG programs and which was also predictive for mortality in multivariable analyses. The analysis by Zhang et al. found in both men and women that frontal planar QRS|T angle was suitable for risk stratification. ${ }^{6}$ However, other analyses have suggested that spatial QRS|T angle outperforms frontal plane QRS|T angle as a risk predictor for ventricular arrhythmia in defibrillator patients ${ }^{19}$ and as an indicator for heart disease. ${ }^{20}$ Further evaluation of the settings in which frontal plane QRS|T angle is suitable for risk prediction is warranted, especially given the ease with which it can be calculated from a 12-lead ECG.

Among the limitations in our study, we used an approximation for spatial QRS|T angle from the 12-lead ECG that does not incorporate a matrix transformation. While this approach used may not be as precise as matrix-based approaches, ${ }^{21}$ prior data suggests a high correlation between the two approaches. ${ }^{14}$ In addition, we lacked echocardiographic measures of left ventricular function to complement the other clinical predictors in our analyses. Therefore, we cannot compare the prognostic utility of QRS|T angle to this measure of risk estimation. Also, data were unavailable for specific non-fatal cardiovascular outcomes such as ventricular arrhythmia, which has been associated with abnormal QRS|T angle in high-risk cohorts. ${ }^{19,22}$

\section{Supplementary Material}

Refer to Web version on PubMed Central for supplementary material. 


\section{Acknowledgments}

This work is supported by grants (P01 HL088117 and 1RC2 HL101663-01) from the National Institutes of Health. Dr. Whang is funded by a Scientist Development Grant from the American Heart Association Founders Affiliate. Dr. Levitan was funded by the Agency for Healthcare Research and Quality (K12HS019465).

\section{References}

1. Oikarinen L, Nieminen MS, Viitasalo M, Toivonen L, Jern S, Dahlof B, Devereux RB, Okin PM. QRS duration and QT interval predict mortality in hypertensive patients with left ventricular hypertrophy: the Losartan Intervention for Endpoint Reduction in Hypertension Study. Hypertension. 2004; 43:1029-1034. [PubMed: 15037560]

2. Okin PM, Devereux RB, Fabsitz RR, Lee ET, Galloway JM, Howard BV. Principal component analysis of the $\mathrm{T}$ wave and prediction of cardiovascular mortality in American Indians: the Strong Heart Study. Circulation. 2002; 105:714-719. [PubMed: 11839627]

3. Rautaharju PM, Ge S, Nelson JC, Marino Larsen EK, Psaty BM, Furberg CD, Zhang ZM, Robbins J, Gottdiener JS, Chaves PH. Comparison of mortality risk for electrocardiographic abnormalities in men and women with and without coronary heart disease (from the Cardiovascular Health Study). Am J Cardiol. 2006; 97:309-315. [PubMed: 16442387]

4. Chugh SS, Reinier K, Singh T, Uy-Evanado A, Socoteanu C, Peters D, Mariani R, Gunson K, Jui J. Determinants of prolonged QT interval and their contribution to sudden death risk in coronary artery disease: the Oregon Sudden Unexpected Death Study. Circulation. 2009; 119:663-670. [PubMed: 19171855]

5. Voulgari C, Tentolouris N. Assessment of the Spatial QRS-T Angle by Vectorcardiography: Current Data and Perspectives. Curr Cardiol Rev. 2009; 5:251-262. [PubMed: 21037841]

6. Zhang ZM, Prineas RJ, Case D, Soliman EZ, Rautaharju PM. Comparison of the prognostic significance of the electrocardiographic QRS/T angles in predicting incident coronary heart disease and total mortality (from the atherosclerosis risk in communities study). Am J Cardiol. 2007; 100:844-849. [PubMed: 17719331]

7. Kardys I, Kors JA, van der Meer IM, Hofman A, van der Kuip DA, Witteman JC. Spatial QRS-T angle predicts cardiac death in a general population. Eur Heart J. 2003; 24:1357-1364. [PubMed: 12871693]

8. Rautaharju PM, Kooperberg C, Larson JC, LaCroix A. Electrocardiographic abnormalities that predict coronary heart disease events and mortality in postmenopausal women: the Women's Health Initiative. Circulation. 2006; 113:473-480. [PubMed: 16449726]

9. Yamazaki T, Froelicher VF, Myers J, Chun S, Wang P. Spatial QRS-T angle predicts cardiac death in a clinical population. Heart Rhythm. 2005; 2:73-78. [PubMed: 15851268]

10. Selvin E, Manzi J, Stevens LA, Van Lente F, Lacher DA, Levey AS, Coresh J. Calibration of serum creatinine in the National Health and Nutrition Examination Surveys (NHANES) 1988-1994, 1999-2004. Am J Kidney Dis. 2007; 50:918-926. [PubMed: 18037092]

11. Levey AS, Stevens LA, Schmid CH, Zhang YL, Castro AF 3rd, Feldman HI, Kusek JW, Eggers P, Van Lente F, Greene T, Coresh J. A new equation to estimate glomerular filtration rate. Ann Intern Med. 2009; 150:604-612. [PubMed: 19414839]

12. Blackburn H, Keys A, Simonson E, Rautaharju P, Punsar S. The electrocardiogram in population studies. A classification system. Circulation. 1960; 21:1160-1175. [PubMed: 13849070]

13. Rautaharju PM, Park LP, Chaitman BR, Rautaharju F, Zhang Z-M. The novacode criteria for classification of ECG abnormalities and their clinically significant progression and regression. Journal of Electrocardiology. 1998; 31:157-187. [PubMed: 9682893]

14. Rautaharju PM, Prineas RJ, Zhang ZM. A simple procedure for estimation of the spatial QRS/T angle from the standard 12-lead electrocardiogram. J Electrocardiol. 2007; 40:300-304. [PubMed: 17292386]

15. Atsma F, Bartelink ML, van der Schouw YT, Kors JA, Grobbee DE. Elevated blood pressure and electrocardiographic frontal $\mathrm{T}$ axis and spatial QRS-T angle changes in postmenopausal women. $\mathrm{J}$ Electrocardiol. 2008; 41:360-364. [PubMed: 18353347] 
16. Dilaveris P, Gialafos E, Pantazis A, Synetos A, Triposkiadis F, Gialafos J. The spatial QRS-T angle as a marker of ventricular repolarisation in hypertension. J Hum Hypertens. 2001; 15:63-70. [PubMed: 11224004]

17. Voulgari C, Tentolouris N, Moyssakis I, Dilaveris P, Gialafos E, Papadogiannis D, Votteas V, Cokkinos DV, Stefanadis C, Katsilambros N. Spatial QRS-T angle: association with diabetes and left ventricular performance. Eur J Clin Invest. 2006; 36:608-613. [PubMed: 16919042]

18. Dilaveris P. The effects of cigarette smoking on the heterogeneity of ventricular repolarization. The American heart journal. 2001; 142:833-837.

19. Borleffs CJ, Scherptong RW, Man SC, van Welsenes GH, Bax JJ, van Erven L, Swenne CA, Schalij MJ. Predicting ventricular arrhythmias in patients with ischemic heart disease: clinical application of the ECG-derived QRS-T angle. Circ Arrhythm Electrophysiol. 2009; 2:548-554. [PubMed: 19843923]

20. Brown RA, Schlegel TT. Diagnostic utility of the spatial versus individual planar QRS-T angles in cardiac disease detection. J Electrocardiol. 2011; 44:404-409. [PubMed: 21353236]

21. Schreurs CA, Algra AM, Man SC, Cannegieter SC, van der Wall EE, Schalij MJ, Kors JA, Swenne CA. The spatial QRS-T angle in the Frank vectorcardiogram: accuracy of estimates derived from the 12-lead electrocardiogram. J Electrocardiol. 2010; 43:294-301. [PubMed: 20417936]

22. Pavri BB, Hillis MB, Subacius H, Brumberg GE, Schaechter A, Levine JH, Kadish A. Prognostic value and temporal behavior of the planar QRS-T angle in patients with nonischemic cardiomyopathy. Circulation. 2008; 117:3181-3186. [PubMed: 18574059] 

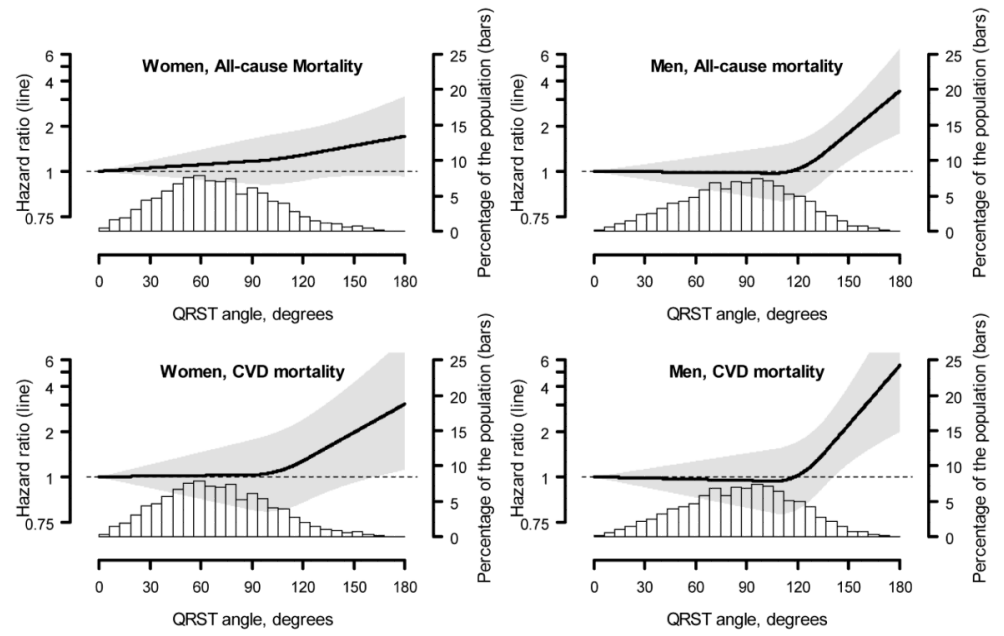

Figure 1.

Multivariable adjusted hazard ratios for all-cause (top panels) and cardiovascular mortality (bottom panels) associated with spatial QRS|T angle, modeled as a continuous variable using restricted quadratic splines. Spline knots were placed at the $75^{\text {th }}$ and $95^{\text {th }}$ percentiles of the spatial QRS/T angle distribution for women $\left(90^{\circ}\right.$ and $121^{\circ}$, respectively) and men $\left(107^{\circ}\right.$ and $136^{\circ}$, respect ively).

Multivariable adjustment includes age, race/ethnicity, sex, body mass index, physical inactivity, current smoking, systolic blood pressure, antihypertensive medication use, heart rate, diabetes, total and HDL-cholesterol, cholesterol lowering medication use, C-reactive protein $\geq 3 \mathrm{mg} / \mathrm{L}$, reduced estimated glomerular filtration rate, albuminuria, and a history of stroke. 
Table 1

Characteristics of NHANES III participants by spatial QRS|T angle.

\begin{tabular}{|c|c|c|c|}
\hline \multirow[b]{2}{*}{ WOMEN } & \multicolumn{3}{|c|}{ QRS|T angle (range) } \\
\hline & $\begin{array}{c}\text { Normal } \\
\left(<90^{\circ}\right) \\
(\mathrm{N}=2,796)\end{array}$ & $\begin{array}{c}\text { Borderline } \\
\left(9^{\circ} \text { to } 120^{\circ}\right) \\
(\mathrm{N}=751)\end{array}$ & $\begin{array}{c}\text { Abnormal } \\
\left.(\geq \mathbf{1 2 1})^{\circ}\right) \\
(\mathbf{N}=\mathbf{2 4 3})\end{array}$ \\
\hline Age, years & $56.1(0.4)$ & $57.1(0.9)$ & $60.5(1.1)$ \\
\hline \multicolumn{4}{|l|}{ Race/ethnicity } \\
\hline Non-Hispanic white & $86.5 \%$ & $88.4 \%$ & $83.3 \%$ \\
\hline Non-Hispanic black & $9.7 \%$ & $8.9 \%$ & $14.0 \%$ \\
\hline Mexican-American & $3.8 \%$ & $2.7 \%$ & $2.7 \%$ \\
\hline Physically inactive & $28.9 \%$ & $32.5 \%$ & $36.0 \%$ \\
\hline Current smoking & $19.2 \%$ & $20.3 \%$ & $27.9 \%$ \\
\hline Body mass index $\left(\mathrm{kg} / \mathrm{m}^{2}\right)$ & $27.1(0.2)$ & $27.3(0.4)$ & $28.5(0.7)$ \\
\hline Systolic blood pressure (mmHg) & $125.6(0.5)$ & $130.5(1.1)$ & $136.3(1.7)$ \\
\hline Antihypertensive medication use & $19.0 \%$ & $23.4 \%$ & $38.8 \%$ \\
\hline Heart rate (beats per minute) & $68.6(0.3)$ & $70.9(0.6)$ & $70.7(1.7)$ \\
\hline Total cholesterol (mg/dL) & $219.1(1.1)$ & $227.0(2.2)$ & $228.4(3.6)$ \\
\hline $\begin{array}{l}\text { High-density lipoprotein cholesterol } \\
(\mathrm{mg} / \mathrm{dL})\end{array}$ & $56.2(0.6)$ & $55.9(0.9)$ & $53.4(1.4)$ \\
\hline Cholesterol-lowering medication use & $4.6 \%$ & $4.6 \%$ & $8.0 \%$ \\
\hline C-reactive protein $\geq 3 \mathrm{mg} / \mathrm{L}$ & $38.2 \%$ & $40.1 \%$ & $49.3 \%$ \\
\hline Diabetes mellitus & $5.9 \%$ & $11.8 \%$ & $18.6 \%$ \\
\hline $\begin{array}{l}\text { Estimated glomerular filtration rate }<60 \\
\mathrm{ml} / \mathrm{min} / 1.73 \mathrm{~m}^{2}\end{array}$ & $8.4 \%$ & $10.5 \%$ & $13.5 \%$ \\
\hline Albuminuria $\geq 30 \mathrm{mg} / \mathrm{g}$ & $7.5 \%$ & $13.6 \%$ & $23.5 \%$ \\
\hline \multirow[t]{2}{*}{ Prior history of stroke } & $1.8 \%$ & $1.3 \%$ & $5.4 \%$ \\
\hline & \multicolumn{3}{|c|}{ QRS|T angle (range) } \\
\hline MEN & $\begin{array}{c}\text { Normal } \\
\left(<107^{\circ}\right) \\
\mathbf{N}=\mathbf{2 , 3 4 8}\end{array}$ & 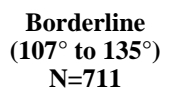 & $\begin{array}{c}\text { Abnormal } \\
\left.(\geq \mathbf{1 3 6})^{\circ}\right) \\
\mathbf{N}=\mathbf{2 0 3}\end{array}$ \\
\hline Age, years & $54.7(0.4)$ & $55.4(0.8)$ & $58.8(1.4)$ \\
\hline \multicolumn{4}{|l|}{ Race/ethnicity } \\
\hline Non-Hispanic white & $87.4 \%$ & $84.7 \%$ & $80.7 \%$ \\
\hline Non-Hispanic black & $8.4 \%$ & $11.5 \%$ & $15.4 \%$ \\
\hline Mexican-American & $4.3 \%$ & $3.9 \%$ & $3.9 \%$ \\
\hline Physically inactive & $16.1 \%$ & $17.5 \%$ & $22.5 \%$ \\
\hline Current smoking & $24.6 \%$ & $29.9 \%$ & $31.1 \%$ \\
\hline Body mass index $\left(\mathrm{kg} / \mathrm{m}^{2}\right)$ & $27.3(0.2)$ & $27.0(0.2)$ & $28.2(0.5)$ \\
\hline Systolic blood pressure (mmHg) & $127.7(0.6)$ & $131.9(1.1)$ & $136.7(2.3)$ \\
\hline Antihypertensive medication use & $14.6 \%$ & $14.9 \%$ & $27.3 \%$ \\
\hline Heart rate (beats per minute) & $66.4(0.4)$ & $67.3(0.6)$ & $69.8(1.4)$ \\
\hline Total cholesterol (mg/dL) & $212.5(1.4)$ & $214.1(2.1)$ & $211.7(5.9)$ \\
\hline $\begin{array}{l}\text { High-density lipoprotein cholesterol } \\
(\mathrm{mg} / \mathrm{dL})\end{array}$ & $45.3(0.5)$ & $45.8(0.9)$ & $46.0(2.1)$ \\
\hline
\end{tabular}




\begin{tabular}{|c|c|c|c|}
\hline \multirow[b]{2}{*}{ MEN } & \multicolumn{3}{|c|}{ QRS|T angle (range) } \\
\hline & $\begin{array}{c}\text { Normal } \\
\left(<107^{\circ}\right) \\
\mathbf{N}=\mathbf{2 , 3 4 8}\end{array}$ & $\begin{array}{c}\text { Borderline } \\
\left(\mathbf{1 0 7}^{\circ} \text { to } 135^{\circ}\right) \\
\text { N=711 }\end{array}$ & $\begin{array}{c}\text { Abnormal } \\
\left(\geq 136^{\circ}\right) \\
\mathbf{N}=\mathbf{2 0 3}\end{array}$ \\
\hline Cholesterol-lowering medication use & $3.8 \%$ & $3.1 \%$ & $9.3 \%$ \\
\hline C-reactive protein $\geq 3 \mathrm{mg} / \mathrm{L}$ & $27.2 \%$ & $31.0 \%$ & $44.1 \%$ \\
\hline Diabetes mellitus & $8.1 \%$ & $12.1 \%$ & $21.5 \%$ \\
\hline $\begin{array}{l}\text { Estimated glomerular filtration rate }<60 \\
\mathrm{ml} / \mathrm{min} / 1.73 \mathrm{~m}^{2}\end{array}$ & $5.0 \%$ & $5.8 \%$ & $7.6 \%$ \\
\hline Albuminuria $\geq 30 \mathrm{mg} / \mathrm{g}$ & $7.6 \%$ & $13.5 \%$ & $23.6 \%$ \\
\hline Prior history of stroke & $2.1 \%$ & $2.3 \%$ & $2.9 \%$ \\
\hline
\end{tabular}

The cut-points for normal, borderline, and abnormal represent the $75^{\text {th }}$ (90 to 120 and 107 to 135 for women and men, respectively) and $95^{\text {th }}$ percentiles ( $\geq 121$ and $\geq 136$ for women and men, respectively) of the spatial QRS|T angle distribution of NHANES III after applying population weights. 
Table 2

Odds ratios for having an abnormal spatial QRS|T angle.

\begin{tabular}{|c|c|c|}
\hline \multirow[t]{2}{*}{ Variable } & \multicolumn{2}{|c|}{$\begin{array}{l}\text { Age-race adjusted } \\
\text { odds ratio }(95 \% \mathrm{CI})\end{array}$} \\
\hline & WOMEN & MEN \\
\hline Age, 10 years & $1.30(1.15-1.48)$ & $1.32(1.11-1.57)$ \\
\hline \multicolumn{3}{|l|}{ Race/ethnicity } \\
\hline Non-Hispanic white & 1 (ref) & 1 (ref) \\
\hline Non-Hispanic black & $1.73(1.21-2.49)$ & $2.08(1.31-3.31)$ \\
\hline Mexican-American & $0.95(0.64-1.42)$ & $1.21(0.64-2.32)$ \\
\hline Physically inactive & $1.18(0.72-1.93)$ & $1.30(0.80-2.12)$ \\
\hline Current smoking & $1.82(1.16-2.85)$ & $1.46(0.89-2.40)$ \\
\hline Body mass index, $5 \mathrm{~kg} / \mathrm{m}^{2}$ & $1.31(1.03-1.65)$ & $1.19(1.02-1.38)$ \\
\hline Systolic blood pressure, $20 \mathrm{mmHg}$ & $1.47(1.20-1.80)$ & $1.51(1.10-2.07)$ \\
\hline Antihypertensive medication use & $2.12(1.48-3.03)$ & $1.82(1.18-2.81)$ \\
\hline Heart rate, 10 beats per minute & $1.13(0.90-1.41$ & $1.23(1.02-1.49)$ \\
\hline Total cholesterol, $40 \mathrm{mg} / \mathrm{dL}$ & $1.09(0.94-1.26)$ & $0.98(0.73-1.31)$ \\
\hline $\begin{array}{l}\text { High-density lipoprotein cholesterol, } 10 \\
\mathrm{mg} / \mathrm{dL}\end{array}$ & $0.88(0.78-1.00)$ & $1.00(0.79-1.25)$ \\
\hline Cholesterol-lowering medication use & $1.63(0.77-3.48)$ & $2.53(1.12-5.71)$ \\
\hline C-reactive protein $\geq 3 \mathrm{mg} / \mathrm{L}$ & $1.48(0.98-2.24)$ & $1.77(1.00-3.11)$ \\
\hline Diabetes mellitus & $2.65(1.71-4.12)$ & $2.46(1.52-3.97)$ \\
\hline $\begin{array}{l}\text { Estimated glomerular filtration rate }<60 \\
\mathrm{ml} / \mathrm{min} / 1.73 \mathrm{~m}^{2}\end{array}$ & $1.15(0.66-2.02)$ & $1.03(0.53-2.02)$ \\
\hline Albuminuria $\geq 30 \mathrm{mg} / \mathrm{g}$ & $2.69(1.83-3.96)$ & $2.67(1.54-4.64)$ \\
\hline \multirow[t]{3}{*}{ History of stroke } & $2.46(0.97-6.25)$ & $0.94(0.39-2.27)$ \\
\hline & \multicolumn{2}{|c|}{$\begin{array}{l}\text { Multivariable adjusted } \\
\text { odds ratio }(95 \% \text { CI })\end{array}$} \\
\hline & WOMEN & MEN \\
\hline Age, 10 years & $1.12(0.93-1.34)$ & $1.16(0.90-1.50)$ \\
\hline \multicolumn{3}{|l|}{ Race/ethnicity } \\
\hline Non-Hispanic white & 1 (ref) & 1 (ref) \\
\hline Non-Hispanic black & $1.30(0.83-2.01)$ & $1.34(0.74-2.42)$ \\
\hline Mexican-American & $0.74(0.48-1.15)$ & $0.98(0.50-1.90)$ \\
\hline Physically inactive & $0.93(0.59-1.44)$ & $1.27(0.80-2.02)$ \\
\hline Current smoking & $1.98(1.16-3.38)$ & $1.55(0.87-2.78)$ \\
\hline Body mass index, $5 \mathrm{~kg} / \mathrm{m}^{2}$ & $1.06(0.90-1.25)$ & $1.16(0.90-1.49)$ \\
\hline Systolic blood pressure, $20 \mathrm{mmHg}$ & $1.28(1.03-1.59)$ & $1.28(0.90-1.83)$ \\
\hline Antihypertensive medication use & $1.43(0.92-2.24)$ & $1.30(0.83-2.04)$ \\
\hline Heart rate, 10 beats per minute & $0.99(0.78-1.27)$ & $1.15(0.90-1.47)$ \\
\hline Total cholesterol, $40 \mathrm{mg} / \mathrm{dL}$ & $0.98(0.87-1.10)$ & $0.91(0.67-1.25)$ \\
\hline $\begin{array}{l}\text { High-density lipoprotein cholesterol, } 10 \\
\mathrm{mg} / \mathrm{dL}\end{array}$ & $0.95(0.85-1.07)$ & $1.10(0.89-1.34)$ \\
\hline Cholesterol-lowering medication use & $1.46(0.67-3.19)$ & $2.44(1.00-5.99)$ \\
\hline
\end{tabular}




\begin{tabular}{|c|c|c|}
\hline & \multicolumn{2}{|c|}{$\begin{array}{l}\text { Multivariable adjusted } \\
\text { odds ratio }(95 \% \mathrm{CI})\end{array}$} \\
\hline & WOMEN & MEN \\
\hline C-reactive protein $\geq 3 \mathrm{mg} / \mathrm{L}$ & $1.04(0.65-1.68)$ & $1.42(0.74-2.73)$ \\
\hline Diabetes mellitus & $1.80(0.93-3.48)$ & $1.83(1.02-3.31)$ \\
\hline $\begin{array}{l}\text { Estimated glomerular filtration rate }<60 \\
\mathrm{ml} / \mathrm{min} / 1.73 \mathrm{~m}^{2}\end{array}$ & $0.97(0.53-1.80)$ & $0.76(0.36-1.60)$ \\
\hline Albuminuria $\geq 30 \mathrm{mg} / \mathrm{g}$ & $1.96(1.27-3.04)$ & $1.68(0.91-3.10)$ \\
\hline History of stroke & $1.82(0.61-5.40)$ & $0.78(0.32-1.88)$ \\
\hline
\end{tabular}

Abnormal QRS|T angle defined as $\geq 121^{\circ}$ for women and $\geq 136^{\circ}$ for men. Multivariable adjustment includes all of the variables listed in the table in a single model. Due to missing data 240 men (7.4\%) and 314 women $(9.0 \%)$ were excluded from multivariable analyses. 
Table 3

Association between borderline and abnormal spatial QRS|T angle and all-cause and cardiovascular mortality.

\begin{tabular}{|c|c|c|c|}
\hline \multirow[b]{2}{*}{ WOMEN } & \multicolumn{3}{|c|}{ QRS|T angle (range) } \\
\hline & $\begin{array}{l}\text { Normal } \\
\left(<90^{\circ}\right)\end{array}$ & $\begin{array}{l}\text { Borderline } \\
\left(9^{\circ} \text { to } 120^{\circ}\right)\end{array}$ & $\begin{array}{c}\text { Abnormal } \\
\left(\geq \mathbf{1 2 1}^{\circ}\right)\end{array}$ \\
\hline \multicolumn{4}{|l|}{ All-cause mortality } \\
\hline Number of deaths (\%) & $743(20.6 \%)$ & $245(25.9 \%)$ & $105(39.1 \%)$ \\
\hline \multicolumn{4}{|l|}{ Hazard ratio $(95 \% \mathrm{CI})$} \\
\hline Demographic adjusted & 1 (ref) & $1.19(0.99-1.44)$ & $1.65(1.20-2.26)$ \\
\hline Multivariable adjusted & 1 (ref) & $1.16(0.94-1.43)$ & $1.30(0.95-1.78)$ \\
\hline \multicolumn{4}{|l|}{ Cardiovascular mortality } \\
\hline Number of deaths $(\%)$ & $304(7.9 \%)$ & $106(9.3 \%)$ & $52(20.2 \%)$ \\
\hline \multicolumn{4}{|l|}{ Hazard ratio $(95 \% \mathrm{CI})$} \\
\hline Demographic adjusted & 1 (ref) & $1.12(0.80-1.56)$ & $2.10(1.19-3.69)$ \\
\hline \multirow[t]{2}{*}{ Multivariable adjusted } & 1 (ref) & $1.08(0.74-1.58)$ & $1.82(1.05-3.14)$ \\
\hline & \multicolumn{3}{|c|}{ QRS|T angle (range) } \\
\hline MEN & $\begin{array}{l}\text { Normal } \\
\left(<107^{\circ}\right)\end{array}$ & $\begin{array}{c}\text { Borderline } \\
\left(\mathbf{1 0 7}^{\circ} \text { to } 135^{\circ}\right)\end{array}$ & $\begin{array}{c}\text { Abnormal } \\
\left(\geq \mathbf{1 3 6}^{\circ}\right)\end{array}$ \\
\hline \multicolumn{4}{|l|}{ All-cause mortality } \\
\hline Number of deaths $(\%)$ & $814(23.1 \%)$ & $265(26.1 \%)$ & $112(51.8 \%)$ \\
\hline \multicolumn{4}{|l|}{ Hazard ratio $(95 \% \mathrm{CI})$} \\
\hline Demographic adjusted & 1 (ref) & $1.07(0.84-1.35)$ & $2.24(1.57-3.19)$ \\
\hline Multivariable adjusted & 1 (ref) & $0.97(0.74-1.27)$ & $1.87(1.29-2.72)$ \\
\hline \multicolumn{4}{|l|}{ Cardiovascular mortality } \\
\hline Number of deaths (\%) & $291(7.9 \%)$ & $102(9.5 \%)$ & $62(24.1 \%)$ \\
\hline \multicolumn{4}{|l|}{ Hazard ratio $(95 \% \mathrm{CI})$} \\
\hline Demographic adjusted & $1(\mathrm{ref})$ & $1.13(0.77-1.65)$ & $3.01(2.10-4.31)$ \\
\hline Multivariable adjusted & 1 (ref) & $1.04(0.69-1.58)$ & $2.21(1.32-3.68)$ \\
\hline
\end{tabular}

The cut-points for normal, borderline, and abnormal represent the 75 th $\left(90^{\circ}\right.$ to $120^{\circ}$ and $107^{\circ}$ to $135^{\circ}$ for women and men, respective ly) and 95 th percentiles $\left(\geq 121^{\circ}\right.$ and $\geq 136^{\circ}$ for women and men, respectively) of the spatia $1 \mathrm{QRS} \mid \mathrm{T}$ angle distribution of NHANES III after applying population weights. Multivariable adjustment includes age, race/ethnicity, sex, body mass index, physical inactivity, current smoking, systolic blood pressure, antihypertensive medication use, heart rate, diabetes, total and high-density lipoprotein cholesterol, cholesterol lowering medication use, C-reactive protein $\geq 3 \mathrm{mg} / \mathrm{L}$, reduced estimated glomerular filtration rate, albuminuria, and a history of stroke. Due to missing data $240 \mathrm{men}(7.4 \%)$ and 314 women $(9.0 \%)$ were excluded from multivariable analyses. 
Table 4

Association between spatial QRS|T angle using pre-specified levels and all-cause and cardiovascular mortality.

\begin{tabular}{|c|c|c|c|}
\hline \multirow[b]{2}{*}{ WOMEN } & \multicolumn{3}{|c|}{ QRS|T angle (range) } \\
\hline & $\begin{array}{l}\text { Normal } \\
\left(<105^{\circ}\right)\end{array}$ & $\begin{array}{l}\text { Borderline } \\
\left(\mathbf{1 0 5}^{\circ} \text { to } 134^{\circ}\right)\end{array}$ & $\begin{array}{c}\text { Abnormal } \\
\left(\geq \mathbf{1 3 5}^{\circ}\right)\end{array}$ \\
\hline \multicolumn{4}{|l|}{ All-cause mortality } \\
\hline Number of deaths (\%) & $883(21.4 \%)$ & $149(26.4 \%)$ & $61(56.1 \%)$ \\
\hline \multicolumn{4}{|l|}{ Hazard ratio $(95 \% \mathrm{CI})$} \\
\hline Demographic adjusted & 1 (ref) & $1.13(0.88-1.44)$ & $2.06(1.53-2.76)$ \\
\hline Multivariable adjusted & 1 (ref) & $1.07(0.84-1.38)$ & $1.46(1.06-2.02)$ \\
\hline \multicolumn{4}{|l|}{ Cardiovascular mortality } \\
\hline Number of deaths (\%) & $364(8.0 \%)$ & $69(11.6 \%)$ & $29(28.1 \%)$ \\
\hline \multicolumn{4}{|l|}{ Hazard ratio $(95 \% \mathrm{CI})$} \\
\hline Demographic adjusted & 1 (ref) & $1.28(0.80-2.05)$ & $2.57(1.61-4.10)$ \\
\hline \multirow[t]{2}{*}{ Multivariable adjusted } & 1 (ref) & $1.26(0.79-2.02)$ & $2.05(1.25-3.37)$ \\
\hline & \multicolumn{3}{|c|}{ QRS|T angle (range) } \\
\hline MEN & $\begin{array}{l}\text { Normal } \\
\left(<105^{\circ}\right)\end{array}$ & $\begin{array}{c}\text { Borderline } \\
\left(\mathbf{1 0 5}^{\circ} \text { to } 134^{\circ}\right)\end{array}$ & $\begin{array}{c}\text { Abnormal } \\
\left(\geq \mathbf{1 3 5}^{\circ}\right)\end{array}$ \\
\hline \multicolumn{4}{|l|}{ All-cause mortality } \\
\hline \multicolumn{4}{|l|}{ Number of deaths (\%) } \\
\hline Hazard ratio $(95 \% \mathrm{CI})$ & $785(23.1 \%)$ & $289(25.7 \%)$ & $117(50.7 \%)$ \\
\hline Demographic adjusted & 1 (ref) & $1.12(0.89-1.40)$ & $2.17(1.57-3.00)$ \\
\hline Multivariable adjusted & 1 (ref) & $0.98(0.75-1.28)$ & $1.78(1.31-2.43)$ \\
\hline \multicolumn{4}{|l|}{ Cardiovascular mortality } \\
\hline \multicolumn{4}{|l|}{ Number of deaths (\%) } \\
\hline Hazard ratio $(95 \% \mathrm{CI})$ & $281(8.0 \%)$ & $110(8.9 \%)$ & $64(23.7 \%)$ \\
\hline Demographic adjusted & 1 (ref) & $1.11(0.76-1.61)$ & $2.89(2.04-4.10)$ \\
\hline Multivariable adjusted & 1 (ref) & $0.97(0.63-1.48)$ & $2.08(1.26-3.46)$ \\
\hline
\end{tabular}

Multivariable adjustment includes age, race/ethnicity, sex, body mass index, physical inactivity, current smoking, systolic blood pressure, antihypertensive medication use, heart rate, diabetes, total and high-density lipoprotein cholesterol, cholesterol lowering medication use, C-reactive protein $\geq 3 \mathrm{mg} / \mathrm{L}$, reduced estimated glomerular filtration rate, albuminuria, and a history of stroke. Due to missing data $240 \mathrm{men}(7.4 \%)$ and 314 women $(9.0 \%)$ were excluded from multivariable analyses. 